\title{
Prevalence and pattern of cardiovascular risk factors in a population in India
}

\author{
Aditya Khetan, ${ }^{1}$ Melissa Zullo, ${ }^{2}$ Vittal Hejjaji, ${ }^{3}$ Dweep Barbhaya, ${ }^{4}$ Sushil Agarwal, ${ }^{5}$ \\ Rishab Gupta, ${ }^{6}$ Sri Krishna Madan Mohan, ${ }^{1}$ Richard Josephson ${ }^{1}$
}

- Additional material is published online only. To view please visit the journal online (http://dx.doi.org/10.1136/ heartasia-2017-010931).

${ }^{1}$ Harrington Heart \& Vascular Institute, University Hospitals Cleveland Medical Centre, Case Western Reserve University, Cleveland, Ohio, USA

${ }^{2}$ Kent State University, Kent, Ohio, USA

${ }^{3}$ Department of Medicine, University Hospitals Cleveland Medical Centre, Case Western Reserve University, Cleveland, Ohio, USA

${ }^{4}$ Seth GS Medical College,

Mumbai, India

${ }^{5}$ Society for Enhanced Health and Access to Treatments, Dalkhola, India

${ }^{6}$ AlIMS, New Delhi, India

Correspondence to

Dr Aditya Khetan, Harrington Heart \& Vascular Institute,

University Hospitals Cleveland Medical Centre, Cleveland, $\mathrm{OH}$ 44106, USA; aditya.khetan@ uhhospitals.org

Received 31 May 2017 Revised 14 August 2017 Accepted 18 August 2017

\section{ABSTRACT}

Background Cardiovascular disease is the leading cause of mortality in India. Since it is largely driven by risk factors such as hypertension, diabetes and smoking, it is important to study the treatment cascade for these conditions and identify areas for improvement.

Methods This is a cross-sectional study from Project SEHAT (Study to Enhance Heart Associated Treatments), an ongoing cluster randomised controlled trial testing the hypothesis that a community health worker-led intervention can improve the control of cardiovascular risk factors in a community in West Bengal, India. For the baseline data, 3556 adults, between the ages of 35 and 70, were screened for hypertension, diabetes and smoking. For hypertension and diabetes, an elevated reading was confirmed on a repeat visit.

Results 18.3\% $(n=650), 9.0 \%(n=317)$ and $14.1 \%$ $(n=500)$ of adults were diagnosed with hypertension, diabetes and smoking, respectively. Overall, $35.0 \%$ $(n=1242)$ adults had at least one of the three risk factors. $55.1 \%(n=358)$ of participants with hypertension and $40.4 \%(n=128)$ of participants with diabetes were unaware of their respective condition. $36.6 \%(n=238)$ of those with hypertension and $58.0 \%(n=184)$ of diabetics were on treatment. $8.2 \%(n=53)$ hypertensives were controlled (blood pressure $<140 / 90 \mathrm{~mm} \mathrm{Hg}$ ) while $13.6 \%(n=43)$ diabetics were controlled (defined as fasting blood sugar $<126 \mathrm{mg} / \mathrm{dL}$ ). Less than $1 \%$ diabetics were on insulin, and average number of medications for a patient with hypertension was 1.2.

Conclusions In our population in semiurban India, one in three adults have a major cardiovascular risk factor, with low control rates. There is a large burden of undiagnosed cardiovascular risk factors and a large gap between treatment and control, which may be explained by lack of treatment intensification.

\section{INTRODUCTION}

Coronary artery disease, chronic obstructive pulmonary disease and stroke are the top three causes of mortality in India, according to the Global Burden of Disease Study, 2010. This is in stark contrast to 1990, when instead of cardiovascular diseases, diarrhoeal diseases and lower respiratory tract infections were the predominant causes of mortality. This increase has largely been mediated by an increase in the prevalence of dietary risks, high blood pressure (BP), tobacco use, diabetes and physical inactivity.

This increase in cardiovascular disease in low-and-middle-income countries (LMICs) such as India has substantially shifted the global burden of cardiovascular disease, with LMICs now contributing to nearly three quarters of all cardiovascular deaths and $82 \%$ of premature mortality. ${ }^{2}$ This burden of major cardiovascular disease and deaths is despite a lower burden of cardiovascular risk factors in LMICs compared with high-income countries. Furthermore, even within low-income countries, rural areas have a higher cardiovascular mortality rate than urban areas. ${ }^{3}$ A recent study in India ${ }^{4}$ showed that in high mortality districts in the country, which are nearly half of the total number of districts in the country, the probability of a person aged $\geq 15$ dying from any cause before the age of 70 was a staggering $62 \%$ for men and 54\% for women. Vascular diseases contributed the largest fraction to this increased mortality in high mortality districts. Part of the reason for such a discrepancy may be poorer control of cardiovascular risk factors.

It is therefore important to study patterns of cardiovascular risk factors, use of proven pharmacological interventions and identify gaps in care that lead to poor risk factor control in low-income countries such as India.

Thus, we aimed to examine the pattern of hypertension, diabetes and tobacco use in a semiurban population in eastern India and to explore possible mediators of poor control for these three conditions.

\section{METHODS}

\section{Study design and participants}

This is a cross-sectional study from Project Study to Enhance Heart Associated Treatments (clinicaltrials. gov number NCT02115711), an ongoing cluster randomised controlled trial to test the hypothesis that a community health worker (CHW)-based approach can improve the control of cardiovascular risk factors in a community in India. It is a single-site study in Dalkhola, which is a town in the state of West Bengal, and is located in the least literate district of the state-Uttar Dinajpur. ${ }^{5}$ It involves 2-year intervention, which mostly consists of supportive home visits by CHWs to increase the control rates of hypertension and diabetes mellitus, while increasing quit rates for smoking.

Twelve clusters were recruited into the study, with the study design described in figure 1 . This paper is a cross-sectional analysis of screened $(n=3556)$ and enrolled participants $(\mathrm{n}=1242)$. Factors associated with prevalence and control of hypertension, diabetes and smoking were examined.

All adults in the 12 clusters between the ages of 35 and 70 were invited for screening, and 3556 adults were screened. Written informed consent was obtained from all participants. The Institutional 


\section{2 clusters randomly assigned to intervention and control}

\section{6 participants screened}

(Age 35-70 years) \\ the}

1242 participants enrolled with at least 1 cardiovascular risk factor

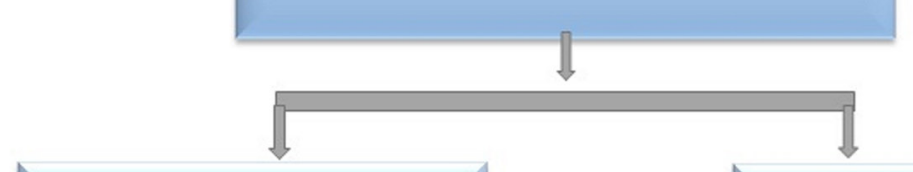

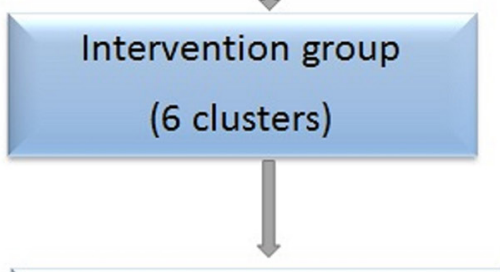

Structured home based intervention over 2 years

\section{Control group}

(6 clusters)

\section{Handout explaining their}

condition + usual care in

the community

Figure 1 Study design.

Review Board at University Hospitals Cleveland Medical Centre (Cleveland, Ohio, USA) and Society for the Promotion of Ethical Clinical Trials (New Delhi, India) approved the study protocol.

\section{Procedures}

The study survey was administered by CHWs who underwent a week-long training session before the start of the screening and a repeat training session of 5 days before the second screening visit. Questions were adapted from the WHO STEPS manual ${ }^{6}$ and focused on hypertension, diabetes and tobacco use. The questionnaire was translated to Bengali for training and administration.

At the screening visit, demographic variables that were assessed included language (Bengali/Hindi); sex (male/female); education (none, $1-8$ years, $>8$ years); marital status (never married/ married); income (measured in rupees per annum as $\leq 50000$, $>50000$ to $\leq 100000,>100000$, refused; 1 US $\$=$ Rs. 65,1 euro=Rs. 70); and work status (does not work/works). BP was measured three times with a calibrated automatic device (Omron HEM-8711 BP monitor, Omron Healthcare) in the sitting position after $5 \mathrm{~min}$ of rest. The readings were spaced $5 \mathrm{~min}$ apart and the final BP was an average of the second and third reading. The blood glucose was measured in the morning in a fasting state with a glucometer (Accu-Chek Performa Nano).

Those with a self-reported history of diabetes or hypertension, an elevated BP ( $>140 / 90 \mathrm{~mm} \mathrm{Hg}$ ) or fasting blood glucose (FBG $>126 \mathrm{mg} / \mathrm{dL}$ ) were visited again for remeasurement 2-4 weeks after the first visit. Individuals were classified as having hypertension if they had elevated BP on both the visits $(>140 / 90 \mathrm{~mm} \mathrm{Hg}$ ) or were on an antihypertensive medication. Similarly, individuals were classified as having diabetes if they had an elevated FBG on both visits (FBG $>126 \mathrm{mg} / \mathrm{dL}$ ) or were on an antidiabetic medication.

Medication use was confirmed by direct examination of the medication blister packs, and to be classified as being on a medication, an individual had to self-report use of the medication on at least one day in the past two weeks.

Additionally, tobacco use status (both smoking and smokeless tobacco) was ascertained in all participants. Participants who reported smoking were asked if they had 'ever made a serious attempt to quit smoking that lasted for at least 24 hours', were 'seriously thinking of quitting smoking within the next 6 months' 
and were 'seriously thinking of quitting smoking within the next 30 days'. Response categories for each question were 'yes' or 'no'. Further details about trial design and procedures have been published elsewhere.'

\section{Statistical analysis}

Prevalence of BP and diabetes control, and smoking attempts/ intention were examined between the intervention and control groups using $\chi^{2}$. Control and smoking variables were examined in bivariate analysis with demographic predictors. Logistic regression analysis examined the relationship between demographic factors and BP control, diabetes control and smoking variables. All analyses were done using STATA V.11.2 statistical software.

\section{Role of the funding source}

The sponsor of the study had a role in the study design but no role in data collection, data analysis, data interpretation or writing of the report. The corresponding author had full access to all the data in the study and had final responsibility for the decision to submit for publication.

\section{RESULTS}

\section{Study participants and risk factor burden}

The majority $(94 \%)$ of the eligible $(n=3785)$ adults participated $(n=3556)$. The sample analysed included 1544 males (43.4\%). There were 1785 participants eligible (high $\mathrm{BP}=1150$; diabetes $=598$; smoking $=539$ ) for a second visit to confirm the diagnosis of hypertension, diabetes and smoking, of which
1676 participated (94\%). Of the 109 participants who could not participate, 7 died in the interval period, 62 refused to participate and 40 could not be found.

Overall, 18.3\% $(n=650), 9.0 \%(n=317)$ and $14.1 \%(n=500)$ of adults were diagnosed with hypertension, diabetes and smoking, respectively (groups are not mutually exclusive). Overall, 35.0\% $(n=1242)$ adults had at least one major cardiovascular risk factor, that is, hypertension, diabetes or smoking. The percentage of cardiovascular risk factors included $83.3 \%$ $(n=1034)$ of participants who had a single risk factor, $15.4 \%$ $(n=191)$ who had two risk factors and $1.4 \%(n=17)$ who had all three risk factors. Chewing tobacco was used daily by $30 \%$ of the screened population $(n=1068)$, and for the purpose of this research was not classified as a major cardiovascular risk factor.

Baseline characteristics of the 3556 participants are described in table 1. Participants who had a cardiovascular risk factor compared with the entire population were more likely to be male (61\% vs 43\%, p<0.001), older (52 years vs 48 years, $\mathrm{p}<0.001$ ) and working $(53 \%$ vs $42 \%, \mathrm{p}<0.001)$.

Increased income $(p<0.001)$ and higher education $(p=0.001)$ were associated with increased prevalence of cardiovascular risk factors. However, $45 \%$ of participants with a cardiovascular risk factor had no formal education and $47 \%$ had an annual income $<$ Rs. 50000 .

\section{Risk factor awareness, treatment and control}

The burden of undetected disease included 55.1\% $(n=358)$ of participants with hypertension and $40.4 \%(n=128)$ of participants with diabetes who were unaware of their condition.

Table 1 Baseline demographics of screened and enrolled participants

\begin{tabular}{|c|c|c|c|}
\hline & $\begin{array}{l}\text { Total }(n=3556) \\
N(\%) \text { or mean (SD) }\end{array}$ & $\begin{array}{l}\text { Enrolled ( } n=1242) \\
N(\%) \text { or mean (SD) }\end{array}$ & $\mathrm{p}$ \\
\hline Interview language & & & 0.005 \\
\hline Bengali & 3038 (85.5) & $1088(87.7)$ & \\
\hline Sex (male) & $1544(43.4)$ & $761(61.3)$ & \\
\hline Age (mean and SD) & $48.3(9.8)$ & $51.9(9.7)$ & \\
\hline $1-5$ & 577 (16.2) & $190(15.3)$ & \\
\hline $6-8$ & 457 (12.9) & 169 (13.6) & \\
\hline $9-10$ & 457 (12.9) & $196(15.8)$ & \\
\hline$>10$ & $346(9.7)$ & $127(10.2)$ & \\
\hline \multicolumn{4}{|l|}{ Community } \\
\hline Refused to disclose & $4(0.11)$ & $3(0.24)$ & \\
\hline Marital status & & & 0.92 \\
\hline Married & 3075 (86.5) & 1073 (86.4) & \\
\hline Not married & $481(13.5)$ & $169(13.6)$ & \\
\hline \multicolumn{4}{|l|}{ Income } \\
\hline$\leq 25000$ & $616(17.3)$ & $214(17.2)$ & \\
\hline $26000-50000$ & 1116 (31.4) & $362(29.2)$ & \\
\hline$>50000-100000$ & $1060(29.8)$ & $387(31.2)$ & \\
\hline$>100000-200000$ & $390(11.0)$ & $163(13.1)$ & \\
\hline$>200000$ & $171(4.8)$ & $65(5.2)$ & \\
\hline
\end{tabular}




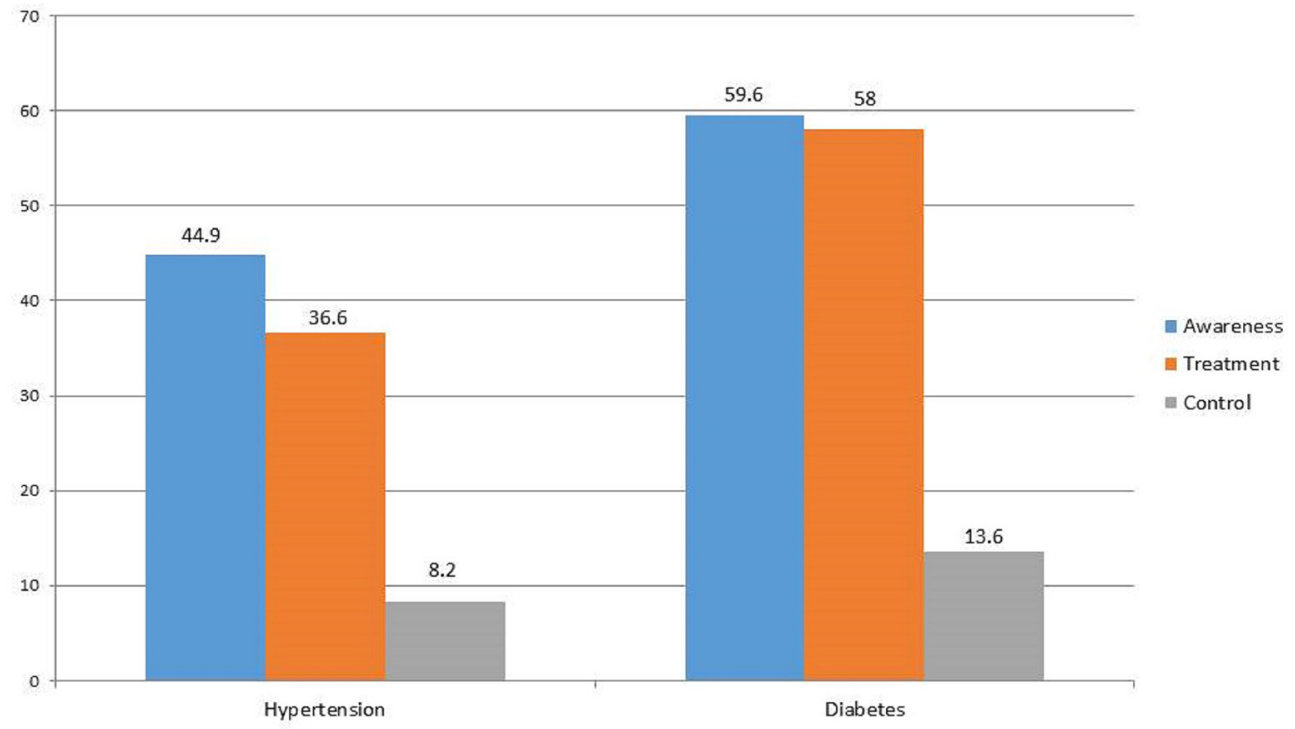

Expressed as percent of participants with each condition

Figure 2 Treatment cascade for hypertension and diabetes.

Overall, 36.6\% $(n=238)$ of those with hypertension were on active drug treatment, while $58.0 \%(n=184)$ of diabetics were on treatment. Control rates were low with $8.2 \%(n=53)$ hypertensives controlled (BP $<140 / 90 \mathrm{~mm} \mathrm{Hg})$ and $13.6 \%(\mathrm{n}=43)$ diabetics controlled (defined as fasting blood sugar $<126 \mathrm{mg} /$ $\mathrm{dL}$ ). This is summarised in figure 2 .

There were no differences between intervention and control groups based on BP control $(\mathrm{p}=0.87)$ or diabetes control $(p=0.65)$. This is summarised in table 2 .

\section{Medication use}

For those using medications, the average number was 1.2 antihypertensive medications per participant and 1.6 antidiabetic medications per participant (figure 3). For details of medication use for hypertension and diabetes, see online supplementary figures S1 and S2, respectively. The use of statins and aspirin in people with at least one major cardiovascular risk factor was $1.7 \%(n=21)$ and $0.5 \%(n=6)$, respectively.

\begin{tabular}{|c|c|c|c|}
\hline & Intervention & Control & $\begin{array}{l}\mathrm{p} \text { (no } \\
\text { clustering) }\end{array}$ \\
\hline \multicolumn{4}{|c|}{ Blood pressure control } \\
\hline Yes & $34(8.3)$ & $19(7.9)$ & \multirow[t]{2}{*}{0.87} \\
\hline No & $376(91.7)$ & $221(92.1)$ & \\
\hline \multicolumn{4}{|c|}{ Diabetes control } \\
\hline Yes & $28(13.0)$ & 15 (14.9) & \multirow[t]{2}{*}{0.65} \\
\hline No & $188(87.0)$ & $86(85.2)$ & \\
\hline \multicolumn{4}{|c|}{ Ever made a serious quit attempt } \\
\hline Yes & $57(21.7)$ & $74(35.1)$ & \multirow[t]{2}{*}{0.001} \\
\hline No & $206(78.3)$ & $137(64.9)$ & \\
\hline \multicolumn{4}{|c|}{ Quit intent in 30 days } \\
\hline Yes & $32(45.7)$ & $39(67.2)$ & \multirow[t]{2}{*}{0.02} \\
\hline No & $38(54.3)$ & $19(32.8)$ & \\
\hline \multicolumn{4}{|c|}{ Quit intent in 6 months } \\
\hline Yes & $70(26.7)$ & $58(27.6)$ & \multirow[t]{2}{*}{0.83} \\
\hline No & $192(73.3)$ & $152(72.4)$ & \\
\hline
\end{tabular}

\section{Tobacco use}

In smokers, $88.0 \%$ smoked bidis $(n=441)$, while $12.6 \%(n=63)$ smoked cigarettes. Bidis are small, thin hand-rolled cigarettes, mostly consumed in South Asia, consisting of unprocessed tobacco usually wrapped in a tendu leaf. In addition, $2.2 \%$ $(\mathrm{n}=11)$ smoked pipes and $0.6 \%(\mathrm{n}=3)$ smoked Hookah. There were 182 smokers (36.4\%) who also used chewing tobacco. Numbers add up to $>100 \%$ since some people used more than one form of smoking tobacco.

Quit attempts included $27.6 \%$ of smokers who had made a previous attempt to quit smoking, 50.5\% who had made an attempt in the past year. Twenty-seven per cent of smokers were thinking of quitting in the next 6 months and $55.5 \%$ of them within the next 30 days.

\section{Demographic associations}

Examining demographic associations (table 3) with BP control showed that overall those with BP control were more likely to be female $(66 \%, p=0.02)$, have $>8$ years of education $(43 \%$, $\mathrm{p}=0.03)$ and a higher income of $>$ Rs. $100000(\sim \$ 1550)$ per annum $(38 \%, \mathrm{p}=0.03)$. Participants with diabetes control were more likely to have an income $>$ Rs. 100000 per annum $(40 \%, \mathrm{p}<0.01)$. Prior quit attempt or intent to quit did not vary according to income, sex, work status or education.

In bivariate analyses of demographics and BP control (table 4), females were 2 (95\% CI 1.1 to 3.6) times as likely as males; those with $>8$ years of education were $2.5(95 \%$ CI 1.3 to 5.2 ) times as likely as those with no education and those with income > Rs. 100000 per annum were $2.4(95 \%$ CI 1.2 to 4.8$)$ times as likely as those making $\leq$ Rs. 50000 per annum to have BP control. Those making > Rs. 100000 per annum were 2.9 (95\% CI 1.3 to 6.4 ) times as likely as those making $\leq$ Rs. 50000 per annum to have diabetes control. Females, compared with males, were 2.8 (95\% CI 1.5 to 5.5) times more likely to report intent to quit smoking in the next six months.

Bengali Hindus and Bengali Muslims were the two largest groups within the community studied. There were no differences between Bengali Hindus $(n=1777)$ and Bengali Muslims $(n=944)$ in terms of sex, age and marital status. 


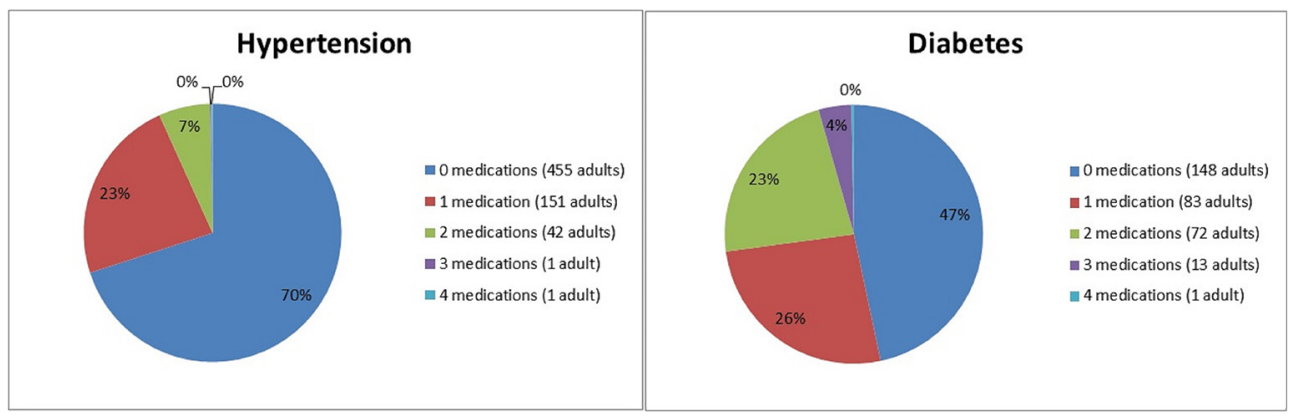

Figure 3 Treatment pattern in hypertension and diabetes.

There was a difference between Hindus and Muslims on education level $29 \%$ of Hindus and $78 \%$ of Muslims had no education; while $15 \%$ of Hindus and $3 \%$ of Muslims had $>10$ years; $\mathrm{p}<0.001$ (mean $=6$ years for Hindus and 1.4 years for Muslims; $\mathrm{p}<0.001)$ ); work status $(57 \%$ and $64 \%$ of Hindus and Muslims, respectively, did not work in the past 12 months; $\mathrm{p}<0.001)$ and income $(48 \%$ of Hindus and 51\% of Muslims made $\leq$ Rs. 50000 per year; $\mathrm{p}<0.001)$.

The prevalence of cardiovascular risk factors differed between Hindus and Muslims with 23\% and 12\%, respectively, having been diagnosed with hypertension $(\mathrm{p}<0.001)$ and $11 \%$ and $5 \%$ having been diagnosed with diabetes $(\mathrm{p}<0.001)$. There was no difference in prevalence of smoking with $15 \%$ of both Hindus and Muslims reporting daily smoking $(p=0.70)$. There was a difference observed in hypertension control with $11 \%(n=46)$ and $4 \%(n=4)$ of Hindus and Muslims, respectively, having $\mathrm{BP}<140 / 90$ (Fisher's exact $\mathrm{p}=0.01$ ). There was no difference between Hindus (12\%) and Muslims (21\%) in diabetes control $(\mathrm{p}=0.13)$.

\section{DISCUSSION}

This research demonstrates three important findings in one community in India. There is a large burden of undiagnosed hypertension and diabetes, uncovering which will likely be essential to making progress on better control of these two conditions. Studies in similar populations that rely solely on self-reported diagnoses of hypertension or diabetes may underestimate the true prevalence of these conditions.

Second, while most people aware of their diagnosis of hypertension and diabetes are on treatment, there is a large gap between treatment and control. We found evidence for lack of treatment intensification, which could possibly explain the gap in a substantial manner. For example, though $58 \%$ of diabetics were on treatment, only $1 \%$ were on insulin. Similarly, for those people with hypertension on medication, the average number of antihypertensive medications was only 1.2. Lack of treatment intensification could be due to either physician inertia ${ }^{89}$ or lack of patient follow-up. Fake or substandard medications are a substantial problem in South Asia, ${ }^{10} 11$ and it is unclear if it could have contributed to the gap between treatment and control in our study. We also found that the use of statins and aspirin in those with at least one cardiovascular risk factor was $<2 \%$. While we did not specifically collect data on prior cardiovascular events in our population, this use of statins/aspirin is far lower than the use of other drugs for hypertension and diabetes, details of which are mentioned in the online supplementary appendix. Potential factors for this low usage are cost of statins (though aspirin is cheaper than virtually all medications for hypertension or diabetes ${ }^{12}$ ), physician inertia, low patient awareness and efforts to minimise pill burden by both physicians and patients.

Third, more than a quarter of smokers had made a previous quit attempt and a similar proportion planned to make a quit

Table 3 Association of demographic factors with blood pressure control, diabetes control and quit attempt

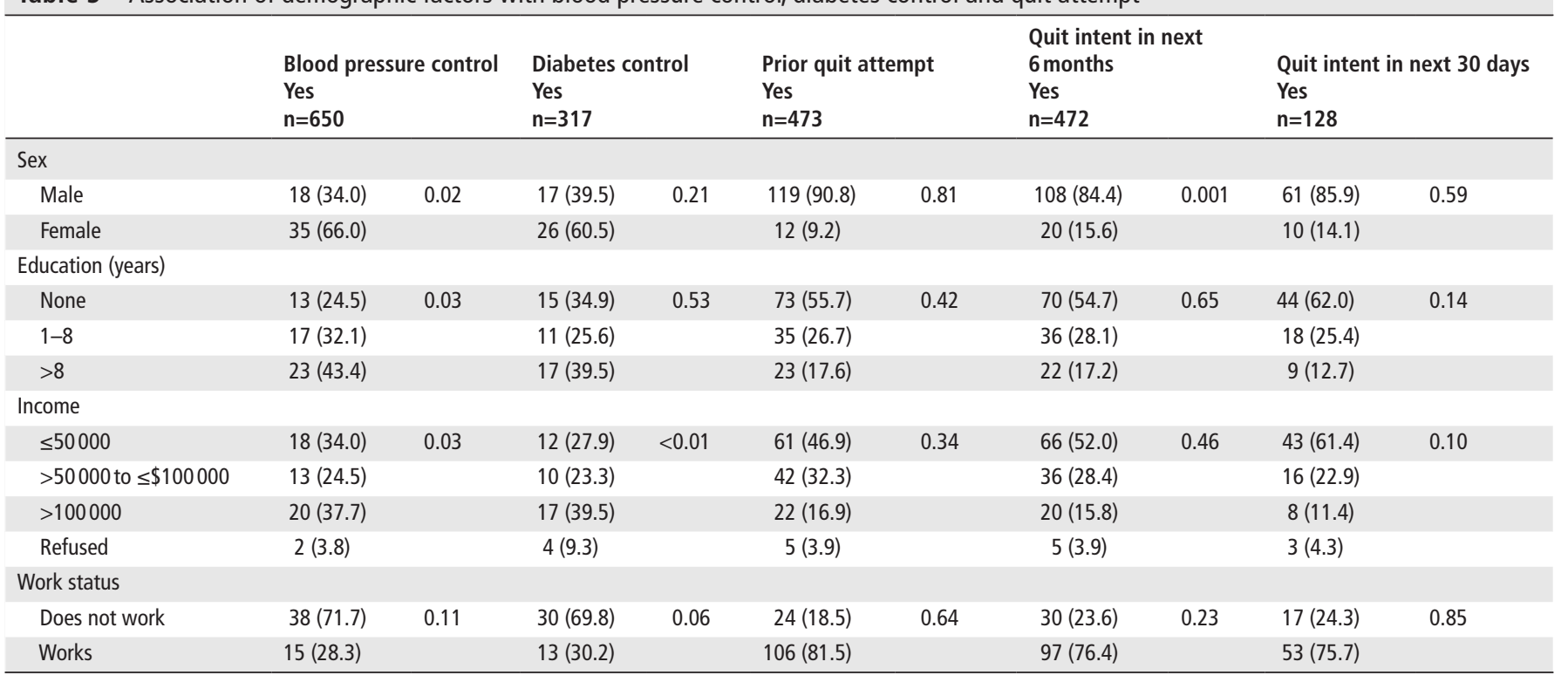


Table 4 Bivariate analysis of demographic factors with blood pressure control, diabetes control and quit attempts

\begin{tabular}{|c|c|c|c|c|c|c|c|c|c|c|}
\hline & \multicolumn{2}{|c|}{ Blood pressure control } & \multicolumn{2}{|c|}{ Diabetes control } & \multicolumn{2}{|c|}{ Quit attempts } & \multicolumn{2}{|c|}{ Quit intent in 30 days } & \multicolumn{2}{|c|}{ Quit intent in 6 months } \\
\hline & & & & & & & & & & \\
\hline Females vs males & 2.0 & 1.1 to 3.6 & 1.5 & 0.79 to 2.9 & 1.1 & 0.51 to 2.2 & 0.77 & 0.30 to 2.0 & 2.8 & 1.5 to 5.5 \\
\hline \multicolumn{11}{|l|}{ Education (years) } \\
\hline None & Ref & & Ref & & Ref & & Ref & & Ref & \\
\hline $1-8$ & 1.9 & 0.92 to 4.1 & 0.63 & 0.27 to 1.5 & 0.73 & 0.46 to 1.2 & 0.59 & 0.26 to 1.3 & 0.80 & 0.50 to 1.3 \\
\hline$>8$ & 2.5 & 1.3 to 5.2 & 0.90 & 0.42 to 1.9 & 0.96 & 0.55 to 1.7 & 0.41 & 0.15 to 1.1 & 0.96 & 0.55 to 1.7 \\
\hline \multicolumn{11}{|l|}{ Income } \\
\hline$\leq 50000$ & Ref & & Ref & & Ref & & Ref & & Ref & \\
\hline$>50000$ to $\leq \$ 100000$ & 1.0 & 0.49 to 2.1 & 1.1 & 0.46 to 2.7 & 1.2 & 0.73 to 1.8 & 0.43 & 0.19 to 0.98 & 0.86 & 0.54 to 1.4 \\
\hline$>100000$ & 2.4 & 1.2 to 4.8 & 2.9 & 1.3 to 6.4 & 1.5 & 0.86 to 2.8 & 0.36 & 0.13 to 0.99 & 1.2 & 1.68 to 2.2 \\
\hline Refused & 1.3 & 0.28 to 5.9 & 4.4 & 1.2 to 16.3 & 2.2 & 0.66 to 7.0 & 0.80 & 0.12 to 5.2 & 1.9 & 0.59 to 6.3 \\
\hline \multicolumn{11}{|l|}{ Work status } \\
\hline Works vs does not work & 0.61 & 0.32 to 1.1 & 0.52 & 0.26 to 1.0 & 1.1 & 0.68 to 1.9 & 0.92 & 0.40 to 2.1 & 0.74 & 0.45 to 1.2 \\
\hline
\end{tabular}

attempt in the next six months. However, availability of smoking cessation resources in India is low, ${ }^{13}$ which may be an important factor in prior unsuccessful quit attempts. Systematically targeting people who are contemplating quitting smoking could lead to a substantial decline in smoking prevalence.

The burden of cardiovascular risk factors in our population in semiurban India is quite high, with one out of three individuals having a major cardiovascular risk factor. This is consistent with estimates from other parts of India, ${ }^{14} 15$ though most of the data are from urban centres. We could not find any studies that looked at prevalence of cardiovascular risk factors in eastern India. The addition of smokeless tobacco or an abnormal lipid panel to the risk profile could further increase these estimates. While smokeless tobacco has been strongly linked to cardiovascular disease, ${ }^{16}{ }^{17}$ little attention is paid to expanding measures that can reduce its prevalence and help people quit, despite the availability of proven measures to reduce smokeless tobacco use. $^{18}$

Coupled with the high burden of cardiovascular risk factors is that $45 \%$ of participants with a cardiovascular risk factor had no formal education and 47\% had an annual income <Rs. 50000 . Given these findings, it is unclear if merely reducing the financial barriers to care will lead to change in behaviour, ${ }^{19}$ especially if not coupled with substantial efforts to educate people with no to little formal education on the basics of chronic disease, and the benefits versus risks/costs of treating an asymptomatic condition.

CHWs have the potential to bridge this gap in information and serve as a vehicle for systematic screening, education and ensuring follow-up. They are usually of a similar socioeconomic background as their patients, which may allow more effective attenuation of the asymmetry of information between patients and the world of healthcare. ${ }^{20} \mathrm{~A}$ few studies that have targeted individual cardiovascular risk factors using CHWs have shown promising results. ${ }^{21}$ However, given the multiplicity of risk factors with high prevalence, progress will likely hinge on the ability of CHWs to successfully mitigate multiple cardiovascular risk factors, thus ensuring a cost-effective holistic approach to community cardiovascular health.

\section{Limitations}

We did not collect information from all participants regarding body mass index, waist size, lipid profile, haemoglobin $\mathrm{A} 1 \mathrm{C}$ or kidney function, which would have provided a more comprehensive evaluation of overall cardiovascular risk. We also did not collect information on medication adherence and use of complementary and alternative medications; both of which likely influence control of hypertension and diabetes. Novel cardiovascular risk factors such as air ${ }^{22}$ or noise pollution ${ }^{23}$ were also not incorporated in our study, though they likely have a substantial effect on overall risk.

\section{CONCLUSIONS}

In this cross-sectional study from a single community in India, we found that there was a large burden of undiagnosed cardiovascular risk factors, a large gap between treatment and control, and a high proportion of people who were interested in quitting smoking. The study will further test whether a CHW-led

\section{Key questions}

What is already known about this subject?

Cardiovascular risk factors account for the top causes of mortality in India. This is in large part due to the low rate of risk factor control. However, the determinants of poor risk factor control have not been well studied.

What does this study add?

In a single semiurban site in India, we found that nearly half of individuals with hypertension and diabetes were unaware of their condition. Furthermore, while most people aware of their diagnosis were on treatment, there was a large gap between treatment and control. We found evidence for lack of treatment intensification, which could possibly be a major determinant of the gap between treatment and control. We also found that $<2 \%$ of people with a major cardiovascular risk factor were on a statin or aspirin. Finally, there was a healthy demand for smoking cessation services, with about a quarter of people who smoked contemplating a quit attempt in the next six months.

\section{How might this impact on clinical practice?}

A plan to improve control of cardiovascular risk factors in India would benefit from a mechanism to systematically diagnose people with hypertension and diabetes in the community. This could be achieved through community health workers. Furthermore, mechanisms to address treatment inertia, both at the physician and patient level, are likely essential to improved risk factor control. Patient and provider education are potential mechanisms to decrease treatment inertia. 
intervention that systematically diagnoses hypertension and diabetes in the community provides treatment support and helps people quit smoking can increase the control of these cardiovascular risk factors.

Acknowledgements The authors thank the staff and CHWs of SEHAT, whose hard work was critical to the study's success. They also thank all study participants, and the wider community of Dalkhola, for their cooperation.

Contributors $A K, R G, S M$ and RJ designed the study. AK, DB and SA conducted the study. MZ did the statistical analysis. AK, MZ, VH and RJ wrote the manuscript. AK obtained funding. All authors reviewed the final manuscript. AK is responsible for the overall content as guarantor.

Funding The study was funded by Marwari Yuva Manch, Dalkhola, India.

Competing interests None declared.

Patient consent Obtained.

Ethics approval University Hospitals IRB (USA) and SPECT IRB (India).

Provenance and peer review Not commissioned; internally peer reviewed.

Data sharing statement The primary data can be made available to anyone who requests it by sending email to the corresponding author.

(c) Article author(s) (or their employer(s) unless otherwise stated in the text of the article) 2017. All rights reserved. No commercial use is permitted unless otherwise expressly granted.

\section{REFERENCES}

1 Lozano R, Naghavi M, Foreman K, et al. Global and regional mortality from 235 causes of death for 20 age groups in 1990 and 2010: a systematic analysis for the Global Burden of Disease Study 2010. Lancet 2012;380:2095-128.

2 Noncommunicable diseases. Geneva: World Health Organisation, 2015. http://www. who.int/mediacentre/factsheets/fs355/en/

3 Yusuf S, Rangarajan S, Teo K, et al. Cardiovascular risk and events in 17 low-, middle-, and high-income countries. N Engl J Med 2014;371:818-27.

4 Ram U, Jha P, Gerland P, et al. Age-specific and sex-specific adult mortality risk in India in 2014: analysis of 0.27 million nationally surveyed deaths and demographic estimates from 597 districts. Lancet Glob Health 2015;3:e767-e775.

5 India, Government of. Provisional Population Totals at a Glance Figure : 2011 - West Bengal [Internet]. 2015 http://censusindia.gov.in/2011-prov-results/prov_data_ products_wb.html
6 Organization WH, others. WHO STEPS surveillance manual: the WHO STEPwise approach to chronic disease risk factor surveillance. 2005 http://apps. who.int/iris/ handle/10665/43376 (cited 2015 Jun 22).

7 Khetan A, Purushothaman R, Zullo M, et al. Rationale and design of a clusterrandomized controlled trial to evaluate the effects of a community health workerbased program for cardiovascular risk factor control in India. Am Heart J 2017;185 http://www.sciencedirect.com/science/article/pii/S0002870316302836

8 Mohan V, Shah S, Saboo B. Current glycemic status and diabetes related complications among type 2 diabetes patients in India: data from the A1chieve study. J Assoc Physicians India 2013;61:12-15.

9 Okonofua EC, Simpson KN, Jesri A, et al. Therapeutic inertia is an impediment to achieving the Healthy People 2010 blood pressure control goals. Hypertension 2006:47:345-51.

10 Khan AN, Khar RK. Current scenario of spurious and substandard medicines in India: a systematic review. Indian J Pharm Sci 2015:77:2

11 Attaran A, Barry D, Basheer S, et al. How to achieve international action on falsified and substandard medicines. BMJ 2012:345:e7381.

12 Karthikeyan G, Xavier D, Prabhakaran D, et al. Perspectives on the management of coronary artery disease in India. Heart 2007:93:1334-8.

13 Murthy P, Saddichha S. Tobacco cessation services in India: recent developments and the need for expansion. Indian J Cancer 2010;47:69.

14 Prabhakaran D, Jeemon P, Roy A. Cardiovascular Diseases in India. Circulation 2016;133:1605-20.

15 Chockalingam $P$, Chockalingam V, Chockalingam A. Time for a pan-India prevention plan for cardiovascular diseases. Indian Heart J 2016;68:252-5.

16 Piano MR, Benowitz NL, Fitzgerald GA, et al. Impact of smokeless tobacco products on cardiovascular disease: implications for policy, prevention, and treatment: a policy statement from the American Heart Association. Circulation 2010:122:1520-44.

17 Teo KK, Ounpuu S, Hawken S, et al. Tobacco use and risk of myocardial infarction in 52 countries in the INTERHEART study: a case-control study. The Lancet 2006:368:647-58

18 Gupta PC, Ray CS. Smokeless tobacco and health in India and South Asia. Respirology 2003:8:419-31.

19 Szczech L. Full coverage for preventive medications after myocardial infarction. Kidney Int 2012:81:225-6.

20 Brownstein JN, Bone LR, Dennison CR, et al. Community health workers as interventionists in the prevention and control of heart disease and stroke. Am J Prev Med 2005;29:128-33.

21 Khetan AK, Purushothaman R, Chami T, et al. The Effectiveness of Community Health Workers in CVD Prevention in LMIC. Glob Heart 2016 http://www.sciencedirect.com/ science/article/pii/S2211816016307013 (cited 2017 Feb 11).

22 Brook RD, Rajagopalan S, Pope CA, et al. Particulate matter air pollution and cardiovascular disease. Circulation 2010;121:2331-78.

23 Münzel T, Gori T, Babisch W, et al. Cardiovascular effects of environmental noise exposure. Eur Heart J 2014;35:829-36. 